\title{
Structural Bioinformatics Analysis of Acid Alpha-Glucosidase Mutants with Pharmacological Chaperones
}

\author{
Sheau Ling Ho \\ Chinese Culture University \\ Taiwan
}

\section{Introduction}

Most lysosomal storage disorders (LSDs) are usually inherited, caused by the deficiency of a single lysosomal hydrolase, leading to the accumulation of the corresponding substrate. LSDs can also result from mutations in proteins involved in the intracellular trafficking of lysosomal enzymes (Carrell \& Lomas, 1997, Kopito \& Ron, 2000, Selkoe, 2003, and Arakawa et al., 2006). Indeed, LSDs are considered as a group of more than sixty diverse inherited disorders. Each of the diseases is due to a specific enzymatic defect (Hodges \& Cheng, 2006, Raben et al., 2009). Pompe disease is one of these LSDs through point mutations (single wild type amino acid substitutions) in the gene that encodes for acid a-glucosidase (GAA). The resulting total or partial deficiency of lysosomal acid a-glucosidase triggers glycogen to accumulate in lysosomes (Alberts et al., 2002, Raben et al., 2002, Bernier et al., 2004, Kroos et al., 2008).

Recently, various small molecule pharmacological chaperones have been discovered to increase stability of such mutant proteins and facilitate their efficient trafficking of lysosomal enzymes. As such, it pointed the way to a new therapeutic approach in LSDs treatment. In this study, we are concerned with revealing the mechanism and accurate structures underlying the defects in the folding behaviors of the involved enzymatic protein mutants, also the way in which they interact with small molecule pharmacological chaperones.

The pharmacological chaperone 1-deoxynojirimycin (DNJ) showed improvement in the treatment of Pompe disease. Yet, experimental data had shown that only a number of GAA mutants responded well to this pharmacological chaperone (Hirschhorn \& Reuser 2001, Petsko \& Ringe, 2004, and Chaudhuri \& Paul 2006, Sugawara et al., 2009, Flanagan et al., 2009). In an effort to improve the stability of mutant enzymes, the understanding on the molecular interaction between the enzyme and the chaperones is very important. Since neighboring residues share physical characteristics, we undertook a detailed study of the surroundings of GAA variants in the structures (Zvelebil, et al., 1987). Thus, we herein aim at discriminating between structural, as opposed to, GAA mutants, based on analysis of their local environments.

Despite the absence of crystallographic data of human acid alpha-glucosidase, we reviewed recently published papers to construct a structural model of human maltase-glucoamylase 
(MGAM) through homology modeling using the structural information (PDB ID: 2QLY) as a template. Note that there are approximate $44 \%$ amino acid sequence identities between the GAA and template. Based on the sequence alignment and the structural mode, our structural model, GAA residues (84-952) were threaded on to the MGAM template. The active site region for both GAA and MGAM overlaid well and the key catalytic residues had high similar spatial alignment (D518/D616 and D445/D542 in GAA and template respectively).

This study involved active site analysis that we applied the proposed model to reveal whether any conformational changes take place at the active site of GAA mutants and molecular docking studies on DNJ which we presented the geometry of the binding site of the complexes of GAA/DNJ and GAA mutants/DNJ. These were done by visual inspection of the atomic models looking at the interaction between the human GAA variants and chaperones, in terms of both binding energy and spatial orientation of the active site. Structural studies should be useful in improving our understanding of enzyme protein stability, molecular recognition and binding and then will help us to further elucidate the molecular basis of Pompe diseas.

\section{Methodology}

\subsection{Structural modelling of the wild-type and mutant human acid $\alpha$-glucosidase}

A structural model of wild-type human acid a-glucosidase was built using molecular modeling software, MIFit (a cross-platform interactive graphics application for molecular modelling), and Molecular Operating Environment, MOE (CCG-Chemical Computing Group Inc.), by means of homology modeling. The structural of human intestinal maltaseglucoamylase (PDB: 2QLY) was used as a template and then energy minimization was carried out. The root-mean-square gradient (RMSD) was computed in terms of all the atoms in a protein backbone and the value was less than $0.6 \AA$ which is indicative of considerable structural similarity.

More than hundred different GAA mutations know to cause Pompe disease are predicted to produce full-length proteins corresponding to a single amino acid substitution. Thus, based on the wild-type human acid a-glucosidase model, the structural models of mutants incorporating the amino acid substitutions were constructed using MIFiT. And the initial model was further refined by energy minimization. However, because of the low amino acids sequence identity between the human acid a-glucosidase and template, the investigations were restricted to a limited region of the enzyme protein.

\subsection{Molecular docking}

\subsubsection{Preparation of ligand}

The initial structure of the pharmacological chaperone 1-deoxynojirimycin (DNJ) (Figure 1) for the docking was generated using ChemDraw Ultra Version 9.0 (CambridgeSoft Corp.). And then geometry optimized ligands were prepared using MOE.

\subsubsection{Docking}

According to the effect of DNJ on responsive GAA mutants, six severe effects of GAA variants (G377R, A445P, L552P, Y575S, E579K, and H612Q) and wild-type GAA were chosen as the receptor for docking (Flanagan et al., 2009). Enzyme proteins and ligand structures were imported into MOE 2010.10 where three-dimensional structures were generated using a course energy minimization protocol and the MMFF94x force field (Halgren, 1996, 1999). 


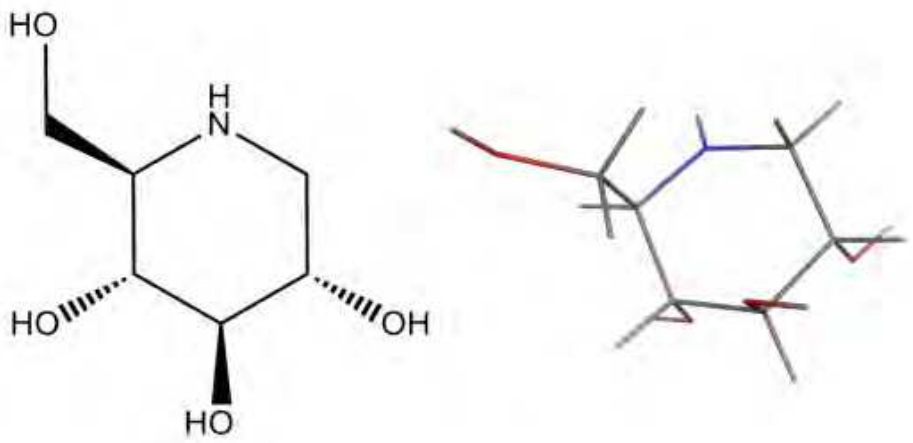

Fig. 1. 3D and 2D visualization of DNJ.

\subsubsection{Structural analysis of GAA mutation}

To exam the effect of atoms, each mutant model was superimposed on the wild-type structure on the basis of the $\mathrm{C} \alpha$ atom by the least-square-mean fitting method (Matsuzawa et al., 2005 and Saito et al., 2008). We assumed that the structure was influenced by an amino acid substitution when the position of an atom in a mutant differed from that in the wildtype structure, thus, such substations were expected to affect neighboring residue and to locally affect the electrostatic surface of the enzyme.

\section{Results and discussion}

\subsection{Structure modelling of human GAA \\ 3.1.1 Wild-type}

As the results showed, our constructed wild-type model of GAA appears to be composed of five domains: a trefoil type- $\Pi$ domain (residues 89-135), an N-terminal b-sandwich domain (residues 136-346), a catalytic $(\beta / \alpha)_{8}$ barrel domain (residues 347-723) with two inserted loops, which include insert 1 (residues 444-491) and insert 2 (residues 522-567) protruding out between $\beta 3$ and $\alpha 3$, and between $\beta 4$ and $\alpha 4$, respectively, a proximal C-terminal domain (residues 724-818) and a distal C-terminal domain (residues 819-952) (Figure 2). The key catalytic activity (D518 and D616) (Hermans et al., 1991, Sugawara et al., 2008 and Sugawara et al., 2009) and sequence motifs of family 31 glycosyl hydrolases were well conserved (Davies \& Henrissat, 1995, and Lovering et al., 2005).

The proposed active-site pocket here was composed to residues of residues W376, W402, D404, I441, D443, W481, W516, D518, M519, F525, R600, W613, D616, D645, F649, and H674 (see Figure 3). Like many other sugar-binding enzymes, there were a lot of hydrophobic residues lining the active-site pocket, including W376, W402, I441, W481, W516, F525, W613, and F649.

\subsubsection{Wild-type vs. mutants}

The six mutant forms of GAA which responded to DNJ severely were superposed with wild-type. After the structure was superimposed, RMSD was computed in terms of the active-site pocket between the wild-type and mutants and the value were found to be less than 0.8 A respectively in between. These varied situations were illustrated in Figure 3. 


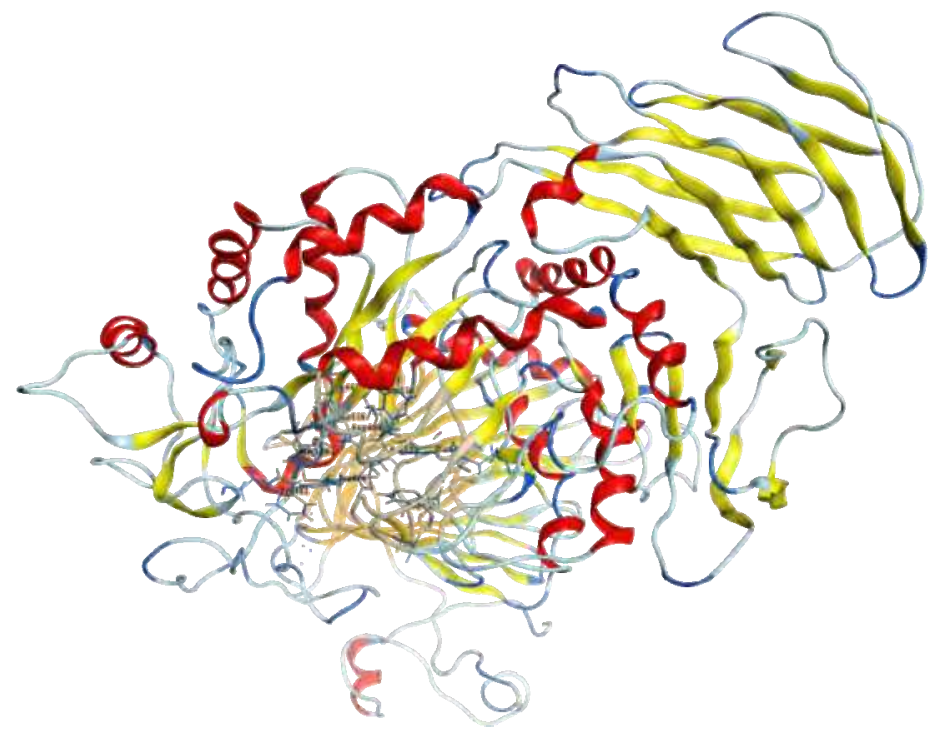

Fig. 2. GAA structural model. A ribbon diagram of GAA structural model. The orange shallow circle area represents the active-site pocket.

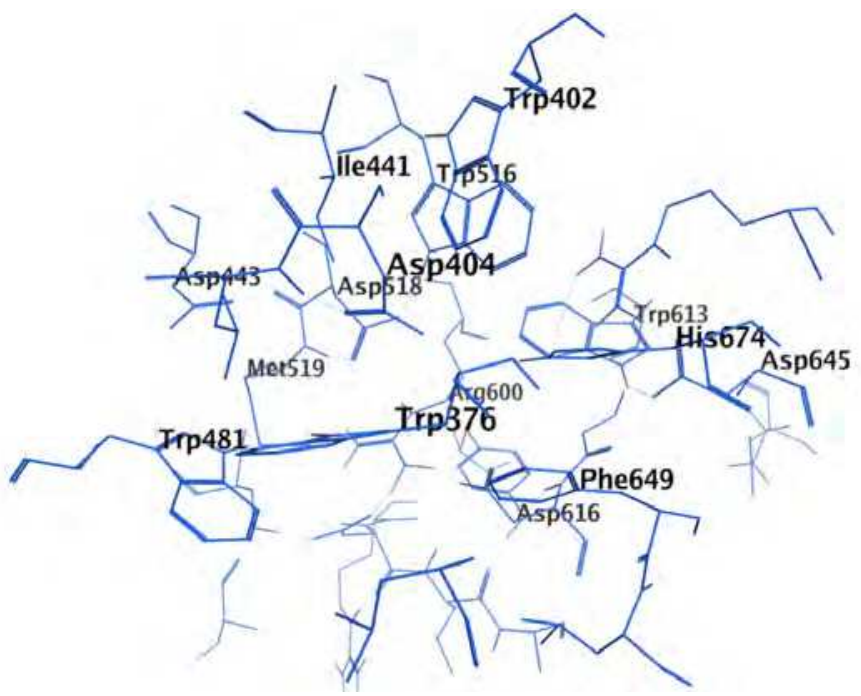

Fig. 3. A close-up view of the active-site pocket (W376, W402, D404, I441, D443, W481, W516, D518, M519, F525, R600, W613, D616, D645, F649, and H674). 


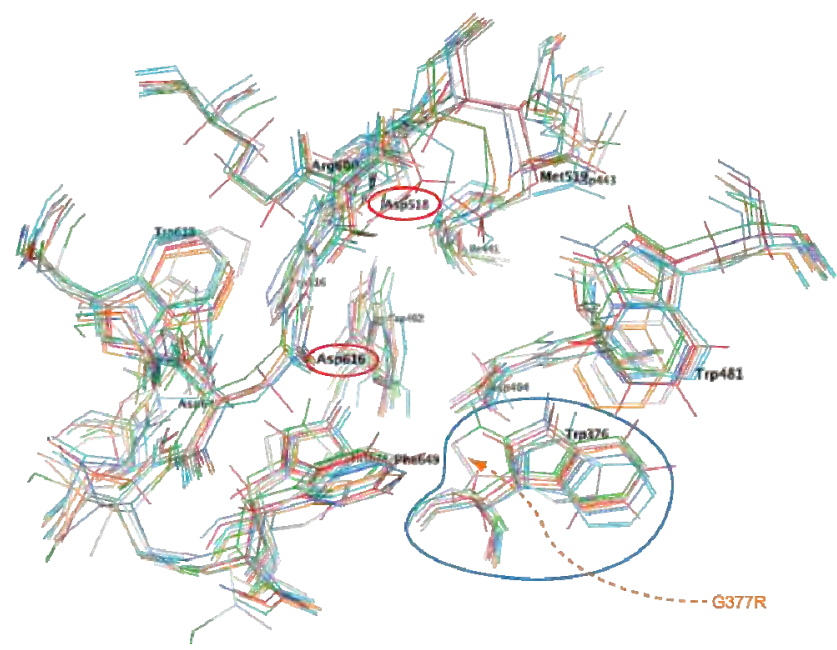

Fig. 4. Superimposed with the corresponding active-site pocket of the wild-type and six mutant variants GAA. The conserved catalytic residues D518/D616 are circled in red. Of GAA variant (G377R), Try turned forwards in the active site.

The comparison results were shown that no significant changes in the conformations of amino acid residues that comprise the active site and mutations of the key catalytic residues were conserved but when mutated as G377R, Try veered forward in active site. This might imply that new drugs can be designed or existing drugs can be modified based on its interaction with the new tyrosine residue (see Figure 4). This observation rules out the possibility of a conformational difference between the mutant and the wild-type enzyme as the derivation cause for the reduction of catalytic activity.

\subsection{Docking}

Molecular docking is utilized for the prediction of protein-ligand complexes which creates possible protein-ligand complex geometries. To understand the interaction between the enzyme and the pharmacological chaperone DNJ, we examined the binding affinity of the DNJ to the enzyme based on the complex geometry and binding energy. In the complex of the DNJ and enzyme model (either wild-type or mutants), the DNJ molecule fitted into the active-site pocket well.

Of the wild-type, residues D404, D518 and D616 were predicted to bind to the hydroxyl groups and the nitrogen of DNJ through hydrogen bonding inside the active-site pocket. Residues W376, I441, W481, W516, M519, W613, and F649 might be involved in the hydrophobic interaction of the DNJ. It is assumed that these residues contribute to the substrate binding specificity. The active-site pocket was apt for DNJ as to both space and binding. We also observed that the interactions between DNJ and the active-site pocket residues of wild-type and mutants; the nitrogen of DNJ was interacted with D518 through hydrogen bonding. (Figure 5 and Figure 6)

The DNJ fit into the active-site pocket well and a limit space between the nitrogen atom of DNJ and the wall of the active-site pocket of wild-type GAA and mutant variants respectively were observed (Figure 7, Figure 8 and Figure 9). 


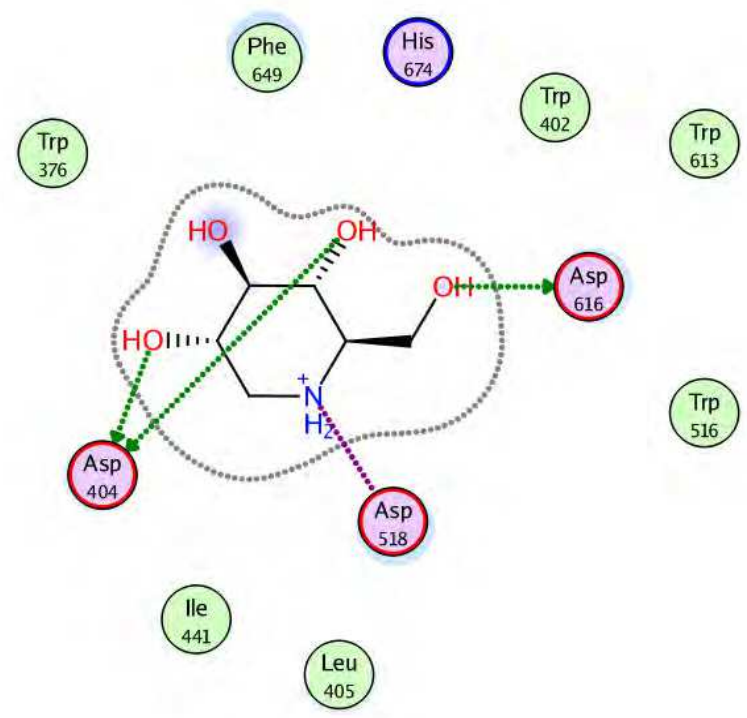

Fig. 5. The interaction diagram between DNJ and the wild-type GAA inside the active-site pocket

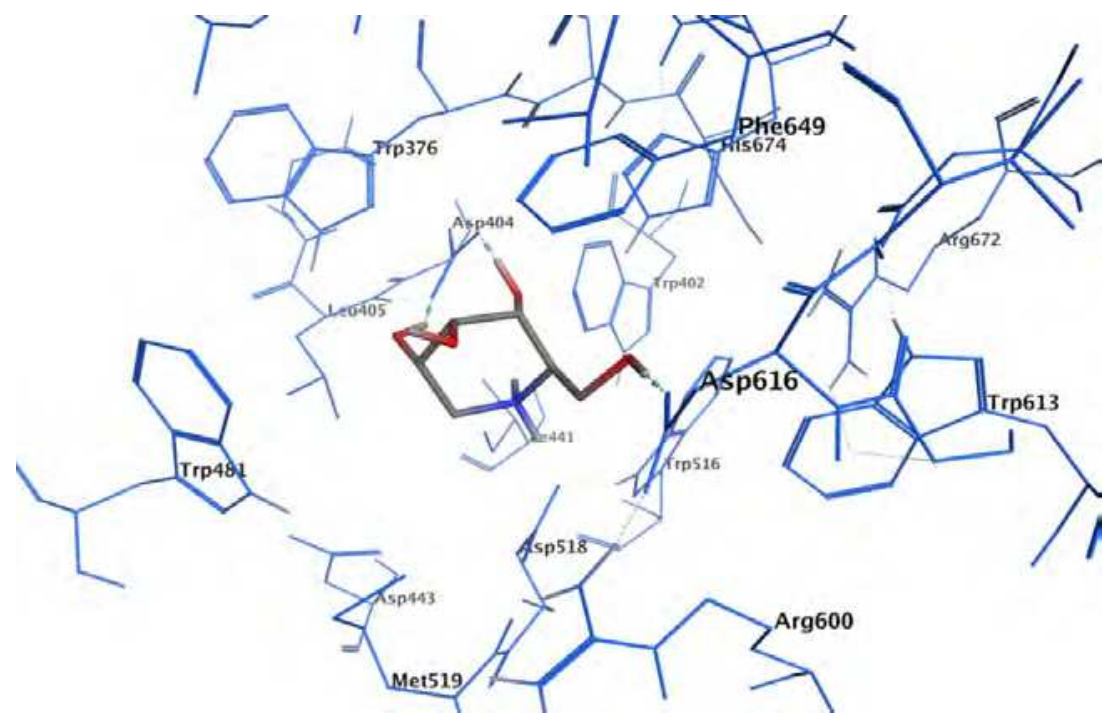

Fig. 6. Structure of wild-type GAA bound to DNJ. 


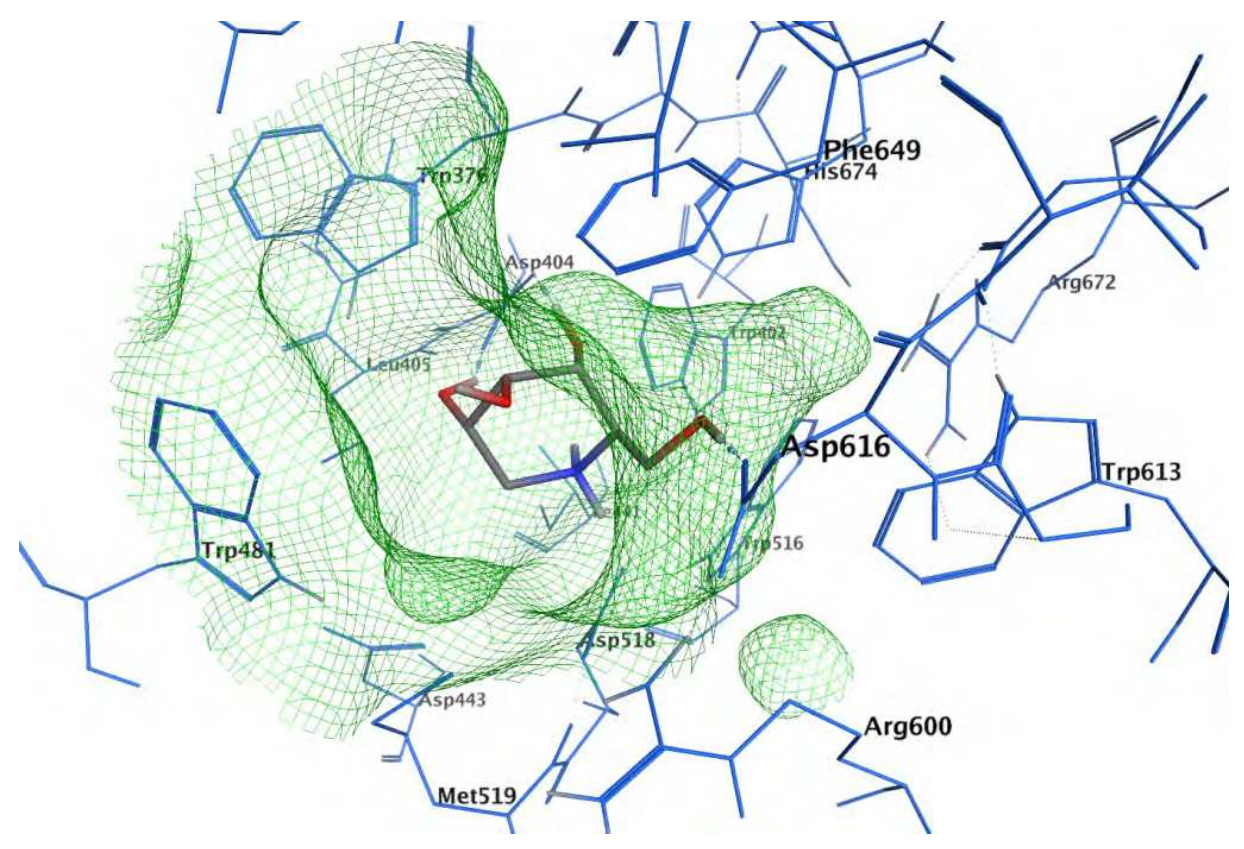

Fig. 7. Surface representation of the active-site pocket of wild-type GAA with bound DNJ. 


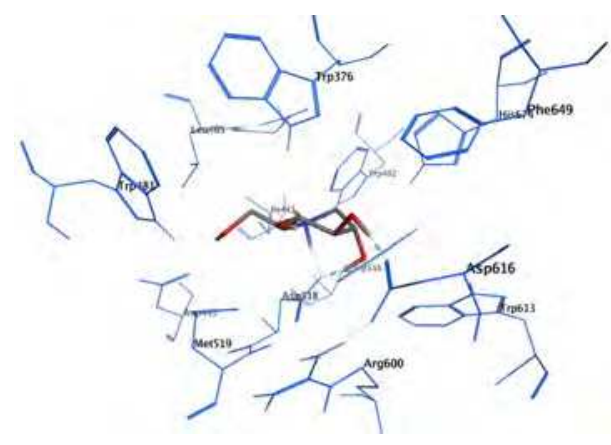

(a) G377R

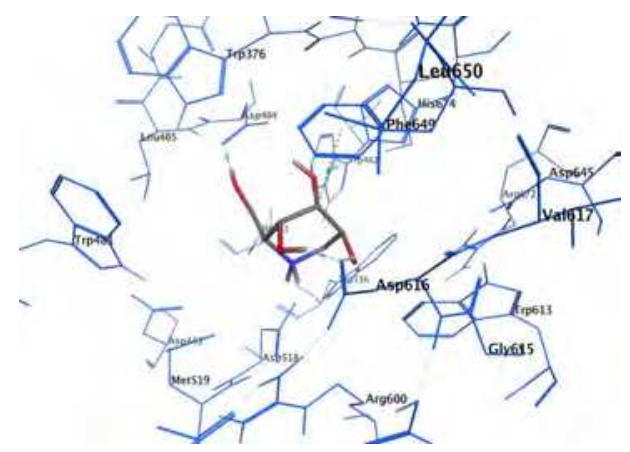

(c) L552P

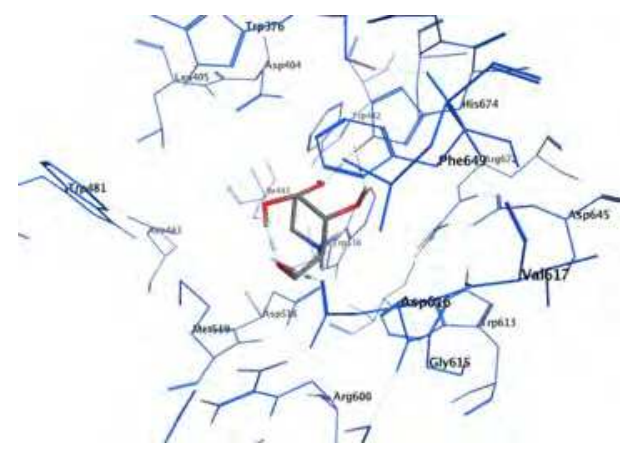

(e) $\mathrm{E} 579 \mathrm{~K}$

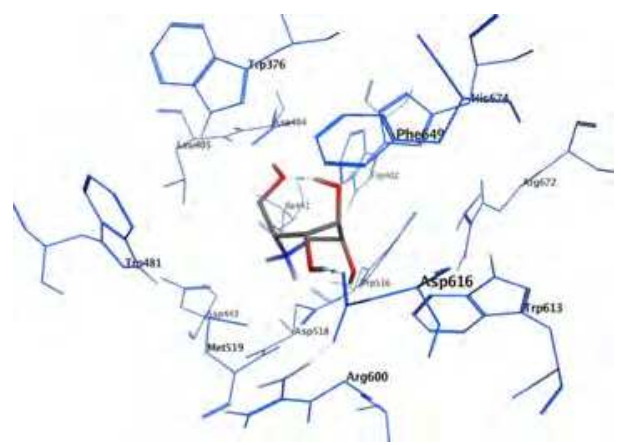

(b) $\mathrm{A} 445 \mathrm{P}$

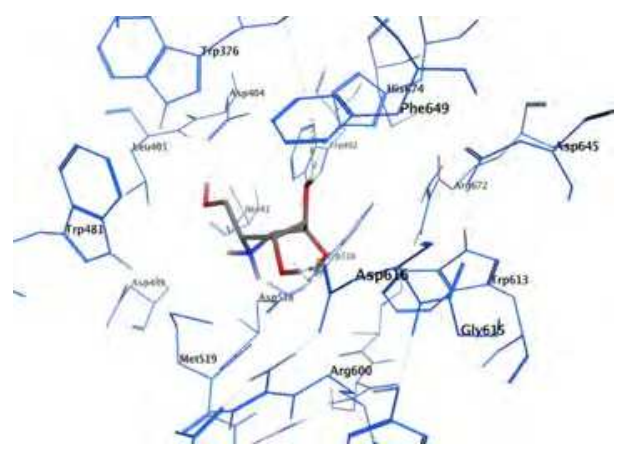

(d) Y575S

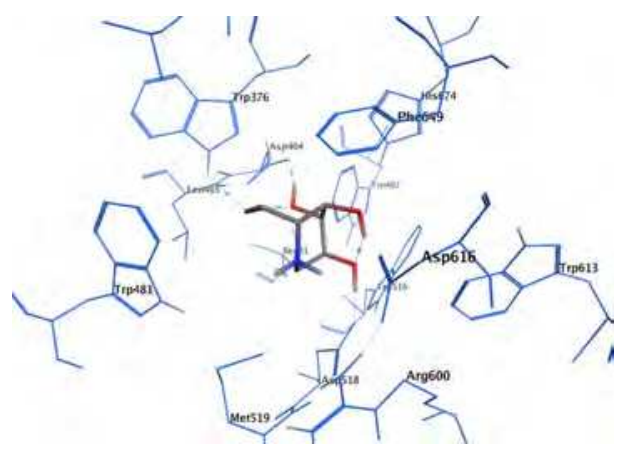

(f) H612Q

Fig. 8. Structure of GAA mutant variants bound to DNJ. 


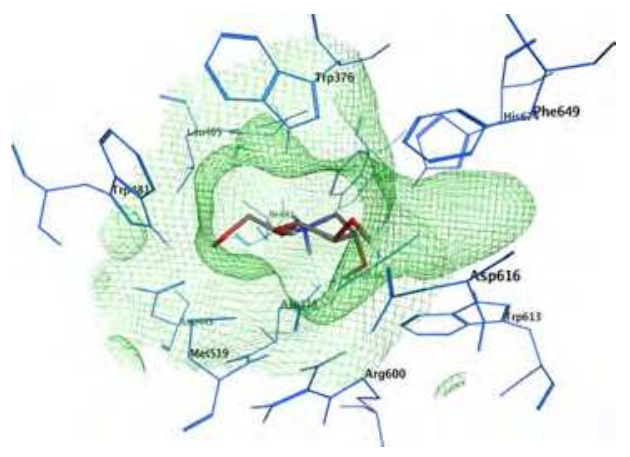

(a) G377R

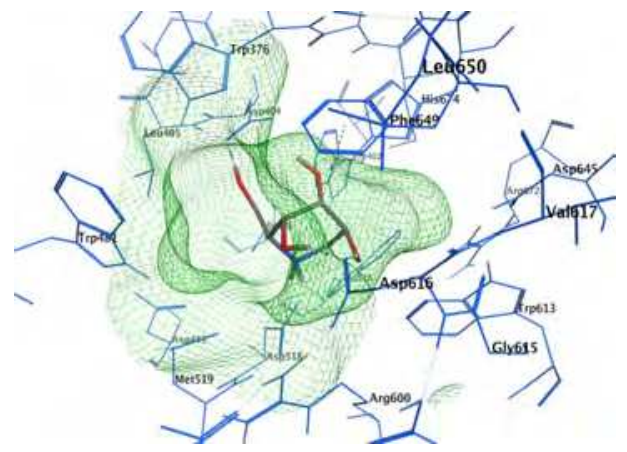

(c) L552P

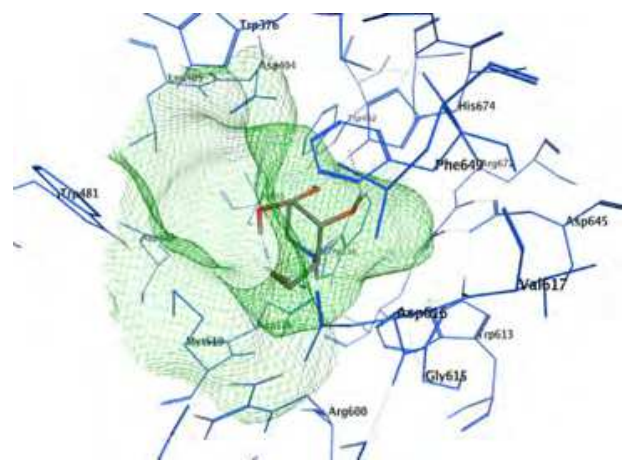

(e) E579K

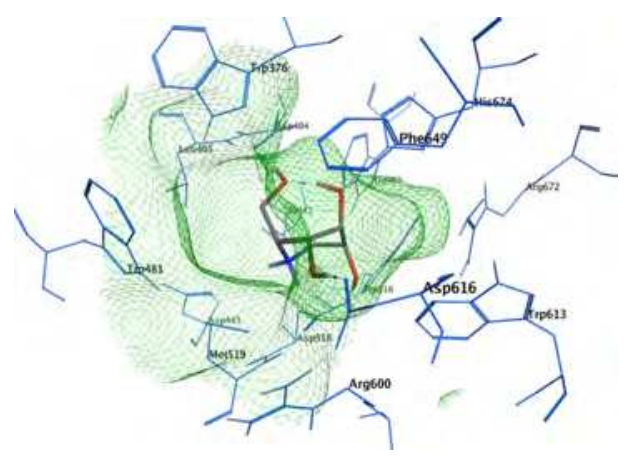

(b) A445P

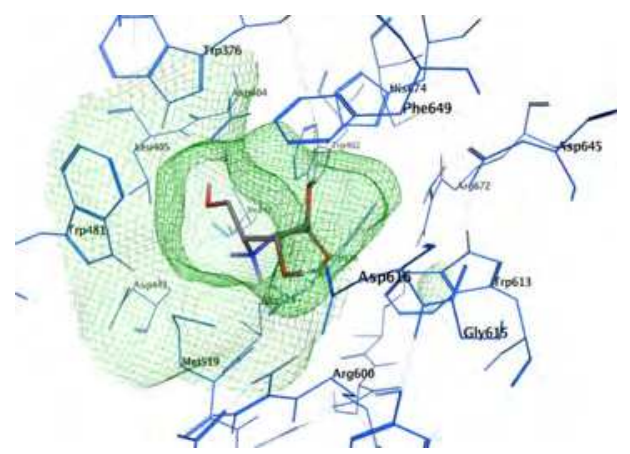

(d) Y575S

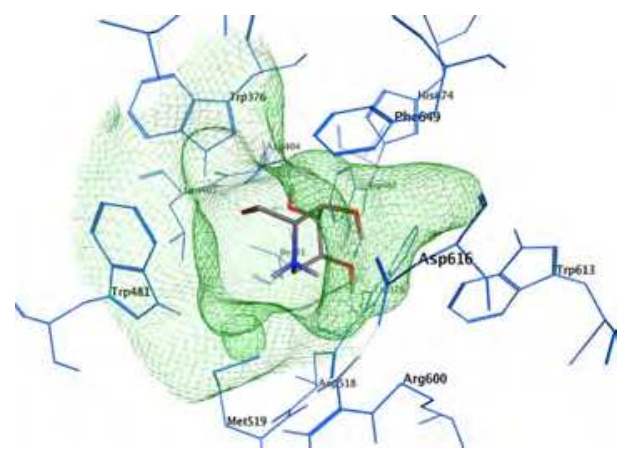

(f) H612Q

Fig. 9. Surface representation of the active-site pocket of GAA variants with bound DNJ. G377R variant shows a larger narrow funnel-shaped region of the active-site cavity. 
We noticed that a narrow funnel-shaped region of the active-site cavity of wild-type GAA was smaller compared with that of other mutant variants. Especially, not only G377R variant showed a larger narrow funnel-shaped region of the active-site cavity compared with that of wild-type GAA or other mutant variants but also of GAA variant (G377R), Try turned forwards in the active site. Thus, it should be possible to modify this molecule to develop a novel derivative suitable for Pompe disease.

The theme of molecular docking is a vital aspect in drug discovery and development. Molecular docking is utilized for the prediction of protein-ligand complexes which predicts the binding affinity of the ligand to the protein based on the complex geometry. The binding energies also reflect the binding affinity of a ligand. The docking results were described in Table 1. The values showed that the binding energy of mutated complex (GAA variants) was higher than that of wild-type complex. Thus, it is interesting to speculate that increase in binding energy due to mutation might decrease the binding affinity of GAA towards DNJ, stabilizing GAA, and modulating its activity.

\begin{tabular}{|c|c|c|c|c|c|c|c|}
\hline \multirow{2}{*}{$\begin{array}{c}\text { Ligand } \\
\text { (DNJ) }\end{array}$} & \multirow{2}{*}{ wild-type } & \multicolumn{7}{|c|}{ Mutants (GAA variants) } \\
\cline { 3 - 8 } & & G377R & A445P & L552P & Y575S & E579K & H612Q \\
\hline $\begin{array}{c}\text { Binding Energy } \\
\text { (kcal/mol) }\end{array}$ & -149.782 & -107.416 & -99.904 & -130.414 & -102.599 & -109.852 & -95.383 \\
\hline
\end{tabular}

Table 1. Energy values obtained in docking calculation.

Still, these binding energies might not yet sufficient for determining binding affinity of ligands or drug candidates associations, some other physical effects such as electrostatics, van der waals, hydrogen bonding, and hydrophobic could affect the binding affinity; those are also needed to be evaluated.

\section{Conclusions}

This work involved active site analysis, molecular docking and binding energy studies. We revealed the mechanism in the folding behaviors of the involved enzymatic protein mutants, and the way they interacted with small molecule pharmacological chaperones based on spatial schematics which provided a basis for experimental validation. The validity of this approach was supported by the identification of some known GAA mutants. Therefore, the conformational changes detected in the distribution of various residues and their constituents around various GAA mutants should be useful in improving our understanding of enzyme protein stability, molecular recognition and binding. Effectively we have demonstrated the corresponding structural conformations associated with GAA wild-type and mutants in their three-dimensional environment. The difference in binding energies might rise due to mutations which could affect the binding affinity of DNJ. And then, it turns out that the complex structures and energy results presented here may provide useful consideration in the therapeutic approaches to these diseases as well as in the design of novel inhibitors associated with sucrose degradation.

\section{Acknowledgments}

The author is grateful to Dr. Wei-Chieh Cheng for his expert advice and useful discussion and Dr. Cheng-Yuan Huang acknowledged for exchanging information. 


\section{References}

Alberts B., Bray D., Hopkin K., Johnson A., Lewis J., Raff M., Roberts K., \& Walter P. (2002). Essential Cell Biology. Garland Science Textbooks, London.

Arakawa T., Ejima D., Kita Y., \& Tsumoto K. (2006). Small molecule pharmacological chaperones: From thermodynamic stabilization to pharmaceutical drugs. Biochim Biophys Acta. Vol. 764:1677-1687.

Bernier V., Lagace M., Bichet D.G.,,\& Bouvier M. (2004). Pharmacological chaperones: potential treatment for conformational diseases. TRENDS in Endocrinology and Metabolism Vol. 15(5): 222-228.

Carrell R.W. \& Lomas, D.A. (1997). Conformational disease, The Lancet Vol. 350: 134-138.

Chaudhuri T.K. \& Paul S. (2006). Protein-misfolding diseases and chaperone-based therapeutic approaches. FEBS J. Vol. 273:1331-1349.

Davies G. \& Henrissat B. (1995). Structures and mechanism of glycosyl hydrolases. Structure. Vol. 3:853-859.

Flanagan JJ., Rossi B., Tang K., Wu X., Mascioli K., Donaudy F., Tuzzi MR., Fontana F., Cubellis MV., Porto C., Benjamin E., Lockhart DJ., Valenzano KJ., Andria G., Parenti G., \& Do HV. (2009). The pharmacological chaperone 1-deoxynojirimycin increases the activity and lysosomal trafficking of multiple mutant forms of acid alpha-glucosidase. Hum Mutat. Vol. 30(12):1683-92.

Halgren T.A. (1996). Merck molecular force field.1. Basis, form, scope, parameterization, and performance of MMFF94. J. Comp. Chem. Vol. 17(5-6):490-519.

Halgren T.A. (1999a). MMFF VI. MMFF94s Option for Energy Minimization Studies. J. Comp. Chem. Vol. 20:720-729.

Halgren T.A. (1999b). MMFF VII. Characterization of MMFF94, MMFF94s, and Other Widely Available Force Fields for Conformational Energies and for IntermolecularInteraction Energies and Geometries. J. Comp. Chem. Vol. 20:730-748.

Hermans Monique M.P., Kroos Marian A., Beeurnen Jos van, Oostra Ben A., \& Reuser Arnold J.J. (1991). Human Lysosomal $\alpha$-Glucosidase characterization of the catalytic site. J. Biol. Chem. Vol. 266(21): 13507-13512.

Hirschhorn R. \& Reuser A.J.J. (2001). Glycogen Storage Disease type II; acid aGlucosidase (Acid Maltase) deficiency. The Metabolic and Molecular Bases of Inherited Disease. D.V. M.D., Editor, Mc Graw-Hill: New York.

Hodges B.L. \& Cheng S.H. (2006). Cell and gene-based therapies for the lysosomal storage diseases. Curr Gene Ther. Vol. 6:227-241.

Kopito R.R. \& Ron D. (2000). Conformational disease. Nat. Cell Biol. Vol. 2: E207-E209.

Kroos M., Pomponio RJ., van Vliet L., Palmer RE., Phipps M., Van der Helm R., Halley D., \& Reuser A. (2008). GAA Database Consortium. Update of the Pompe disease mutation database with 107 sequence variants and a format for severity rating. Hum Mutat. Vol. 6: E13-E26.

Lovering A.L., Lee S. S., Kim Y-W, Withers S.G., \& Strynadka N.C.J. (2005). Mechanistic and Structural Analysis of a Family 31 Glycosidase and Its Glycosyl-enzyme Intermediate. J. Biol. Chem. Vol. 280(3):2105-2115.

Matsuzawa F., Aikawa S., Doi H., Okumiya T., \& Sakuraba H. (2005). Fabry disease: correlation between structural changes in alpha-galactosidase, and clinical and biochemical phenotype. Hum. Genet. Vol. 117:317-328. 
Molecular Operating Environment (MOE) 2010.10. (2010.) Chemical Computing Group, Inc; Montreal, Quebec.

Petsko GA. \& Ringe D. (2004). From structure to function. In Protein Structure and Function. London; New Science Press.

Raben N., Shea L., \& Hill V. (2009). Monitoring Autophagy in Lysosomal Storage Disorders. Methods in Enzymology Vol. 453:417-449.

Raben N., Plotz P., \& Byrne BJ. (2002). Acid alpha-glucosidase deficiency (glucogenosis type II, Pompe disease). Curr Mol Med. Vol. 2:145-166.

Saito S., Ohno K., Sugawara K., \& Sakuraba H. (2008). Structural and clinical implications of amino acid substitutions in N-acetylgalactosamine-4-sulfatase: insight into mucopolysaccharidosis type VI. Mol. Genet. Metab. Vol. 93:419-425.

Selkoe D.J. (2003). Folding proteins in fatal ways. Nature Vol. 426:900-904.

Sugawara K., Ohno K., Saito S., \& Sakuraba H. (2008). Structural characterization of mutant alpha-galactosidases causing Fabry disease. J. Hum. Genet. Vol. 53:812-824.

Sugawara K., Saito S., Sekijima M., Ohno K., Tajima Y., \& Kroos M.A. (2009). Structural modeling of mutant $\alpha$-glucosidases resulting in a processing/transport defect in Pompe disease. J. Hum. Genet. Vol. 54:324-330.

Zvelebil M.J., Barton G.J., Taylor W.R., \& Sternberg M.J. (1987). Prediction of Protein Secondary Structure and Active Sites Using the Alignment of Homologous Sequences. J. Mol Biol. Vol. 195(4):957-961. 


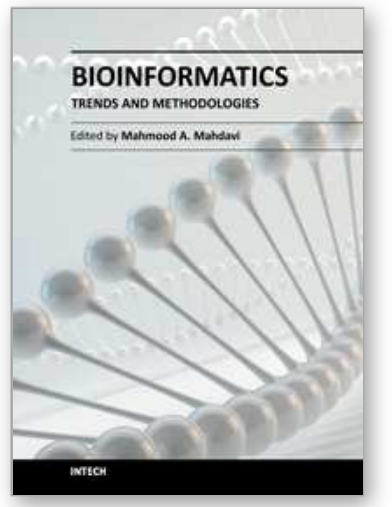

\author{
Bioinformatics - Trends and Methodologies \\ Edited by Dr. Mahmood A. Mahdavi
}

ISBN 978-953-307-282-1

Hard cover, 722 pages

Publisher InTech

Published online 02, November, 2011

Published in print edition November, 2011

Bioinformatics - Trends and Methodologies is a collection of different views on most recent topics and basic concepts in bioinformatics. This book suits young researchers who seek basic fundamentals of bioinformatic skills such as data mining, data integration, sequence analysis and gene expression analysis as well as scientists who are interested in current research in computational biology and bioinformatics including next generation sequencing, transcriptional analysis and drug design. Because of the rapid development of new technologies in molecular biology, new bioinformatic techniques emerge accordingly to keep the pace of in silico development of life science. This book focuses partly on such new techniques and their applications in biomedical science. These techniques maybe useful in identification of some diseases and cellular disorders and narrow down the number of experiments required for medical diagnostic.

\title{
How to reference
}

In order to correctly reference this scholarly work, feel free to copy and paste the following:

Sheau Ling Ho (2011). Structural Bioinformatics Analysis of Acid Alpha-Glucosidase Mutants with Pharmacological Chaperones, Bioinformatics - Trends and Methodologies, Dr. Mahmood A. Mahdavi (Ed.), ISBN: 978-953-307-282-1, InTech, Available from: http://www.intechopen.com/books/bioinformatics-trendsand-methodologies/structural-bioinformatics-analysis-of-acid-alpha-glucosidase-mutants-withpharmacological-chaperones

\section{INTECH}

open science | open minds

\section{InTech Europe}

University Campus STeP Ri

Slavka Krautzeka 83/A

51000 Rijeka, Croatia

Phone: +385 (51) 770447

Fax: +385 (51) 686166

www.intechopen.com

\section{InTech China}

Unit 405, Office Block, Hotel Equatorial Shanghai

No.65, Yan An Road (West), Shanghai, 200040, China

中国上海市延安西路65号上海国际贵都大饭店办公楼 405 单元

Phone: +86-21-62489820

Fax: $+86-21-62489821$ 
(C) 2011 The Author(s). Licensee IntechOpen. This is an open access article distributed under the terms of the Creative Commons Attribution 3.0 License, which permits unrestricted use, distribution, and reproduction in any medium, provided the original work is properly cited. 